\title{
Surveillance for infectious salmon anaemia virus HPR0 in marine Atlantic salmon farms across Scotland
}

\author{
Alastair J. A. McBeath, Nicola Bain, Michael Snow* \\ Marine Scotland Marine Laboratory, PO Box 101, Victoria Road, Aberdeen, AB11 9DB, UK
}

\begin{abstract}
Infectious salmon anaemia virus (ISAV) is a serious and commercially important pathogen of Atlantic salmon. Multiple viruses have been defined based on a highly polymorphic region (HPR) of the haemagglutinin-esterase (HE) protein encoded by genomic segment 6 . The viruses causing disease outbreaks in farms to date all have deletions in this region with respect to a putative ancestral variant with a longer HPR (HPR0). The presence of HPR0 nucleic acid has been detected in many countries including Scotland, where it has mostly been associated with healthy wild and farmed fish. Pathogenic ISAVs appear to have been derived from HPR0 ancestors on multiple independent occasions, which suggests that the presence of HPR0 could represent a risk factor in the re-emergence of infectious salmon anaemia (ISA) disease. In order to better understand this potential risk factor, anonymous samples of gill and heart tissues from marine Atlantic salmon farms throughout Scotland were collected and screened for the presence of ISAV RNA. Since it has not been possible to isolate HPR0 in conventional ISA-permissive cell cultures, a sensitive real-time RT-PCR method was employed for the detection of viral RNA. DNA sequencing was carried out on the positive samples to determine their HPR sequence. ISAV RNA was detected in 6 samples originating from 4 different locations and sequence analysis indicated the viruses were of the HPR0 type. Full length segment 6 sequence analysis of 1 positive sample indicated that it was most similar to a European genotype sequence previously obtained from North America.
\end{abstract}

KEY WORDS: Infectious salmon anaemia virus - HPR0 - Scotland - Real-time PCR - Segment 6 . Phylogeny $\cdot$ Salmo salar

Resale or republication not permitted without written consent of the publisher

\section{INTRODUCTION}

Infectious salmon anaemia (ISA) is a commercially important disease which has exerted a significant impact on Atlantic salmon Salmo salar aquaculture worldwide. It has been reported in Norway (Thorud \& Djupvik 1988), Canada (Mullins et al. 1998, Bouchard et al. 1999, Lovely et al. 1999), the USA (Bouchard et al. 2001), Scotland (Rodger et al. 1998), Chile (Kibenge et al. 2001a, Godoy et al. 2008) and the Faroe Islands (Anonymous 2000). The aetiological agent, infectious salmon anaemia virus (ISAV), belongs to the genus Isavirus of the family Orthomyxoviridae and possesses a genome comprised of 8 single-stranded RNA segments (Mjaaland et al. 1997). The sixth largest gene segment encodes a haemagglutinin-esterase (HE) protein which mediates both receptor binding (Krossøy et al. 2001, Rimstad et al. 2001) and receptor destroying activities (Falk et al. 2004) and may also promote fusion activity (Aspehaug et al. 2005).

A highly polymorphic region (HPR) limited to a 35 amino acid stretch has been identified within the ISAV HE protein (Devold et al. 2001, Kibenge et al. 2001b, Krossøy et al. 2001, Rimstad et al. 2001, Mjaaland et al. 2002, Falk et al. 2004). Based on this region, 24 differing predicted protein sequences have been identified in Europe and 4 in North America (Nylund et al. 2007). The observed differences in this polymorphic region can all be explained as deletions (Mjaaland et al. 2002) from a putative ancestral sequence (HPR0) which was 
first identified in asymptomatic wild fish in Scotland (Cunningham et al. 2002). All currently characterised isolates from ISA disease outbreaks have deletions in their HPR with respect to the HPR0, which strongly indicates that this region is important in ISAV pathogenecity in farmed Atlantic salmon (Mjaaland et al. 2005). An alternative theory involving insertions into the HPR resulting in viral attenuation has also been proposed (Kibenge et al. 2007).

Slightly different HPR0 sequences have been detected in all the major Atlantic salmon growing regions of the Northern Hemisphere including Norway, Scotland, the Faroe Islands and Canada (Cunningham et al. 2002, Cook-Versloot et al. 2004, Christiansen \& Østergård 2007, Nylund et al. 2007). While the HPR0 subtype has been reported in both wild and farmed Atlantic salmon, it has not been associated with clinical disease characteristic of ISA. Its presence has generally been detected in asymptomatic fish, with the exception of association with proliferative gill inflammation in some instances (FRS 2005, Nylund et al. 2007, Markussen et al. 2008).

Although the presence of ISAV HPR0 may not cause disease, its presence is of concern with respect to the potential re-emergence of ISA disease-causing variants in Scotland. The number and diversity of HPR0 variants circulating within the aquaculture industry indicates that emergence of pathogenic variants within aquaculture has likely occurred on numerous and independent occasions. Furthermore, the selective environment of aquaculture has previously been shown to promote a rapid evolution of RNA viruses (Einer-Jensen et al. 2004).

Following the eradication of ISA disease from the 1998-99 outbreak in Scotland, some evidence for the continued presence of viral RNA in Scottish waters has been detected (Cunningham et al. 2002, FRS 2005), although targeted surveillance aimed at detection of ISAV HPR0 had not been conducted. Nylund et al. (2007) identified evidence suggesting that nearly all marine production sites in Norway contained salmon that were positive for ISAV infection, despite only around 15 sites developing ISA disease annually. Furthermore, extensive evidence for viral presence, suggested to be HPR0, has been demonstrated in freshwater (Plarre et al. 2005, Nylund et al. 2007). Given such evidence, the status of Atlantic salmon farms in Scotland with respect to ISAV is clearly an important issue to address. An assessment of the distribution of ISAV HPR0 across Scotland will help understand and manage the risk posed by its presence. Whether the presence of HPR0 was a contributing factor to the recent isolation of ISAV in the Burra region of the Shetland Islands remains to be determined (FRS 2009).
Since ISAV HPR0 has not been cultured to date, realtime PCR of segment 8 and subsequent sequencing of segment 6 from positive samples was applied to the detection of ISAV variants within the Scottish Atlantic salmon marine aquaculture industry. Surveillance was conducted anonymously and organs known to harbour HPR0 ISAV (gill and heart) were assayed. The present study details the results of surveillance for ISAV within Atlantic salmon aquaculture and discusses the implication of findings with respect to the potential for reemergence of ISA disease in Scotland.

\section{MATERIALS AND METHODS}

Surveillance of Scottish marine Atlantic salmon farms for ISAV. Sample collection: Samples were collected anonymously from 36 sites across Scotland by the Marine Scotland Fish Health Inspectorate. Each site was randomly assigned a unique code before provision of samples to lab staff to ensure anonymity. Codes were based on locations within Scotland: northwest mainland (NWM), southwest mainland (SWM), Western Isles (WI) and Orkney and Shetland Isles (OS). At each site, separate gill and heart tissue samples were collected from 30 fish in 6 pools ( $n=5$ fish per pool, labelled a to f for each tissue). Tissues were sampled in RNAlater (Sigma) and stored at $-20^{\circ} \mathrm{C}$ upon arrival at the lab.

RNA extraction: Total RNA was extracted from tissue pools using the M48 BioRobot extraction system and the MagAttract RNA tissue mini M48 Kit (Qiagen) following the manufacturer's protocol with some minor deviations. For processing reasons, tissue pool pairs a $\& \mathrm{~b}, \mathrm{c} \& \mathrm{~d}$, and e \& f were combined prior to homogenisation to give 3 pools each $(n=10)$ of gill and heart tissue per location, designated p1 to 3 . Sample tissue weights were recorded prior to addition of $1 \mathrm{ml}$ RLT buffer (Qiagen) and $\beta$-mercaptoethanol (Sigma). Homogenisation was carried out using the Tissue Lyser system (Qiagen). The quantity of homogenate equating to $5 \mathrm{mg}$ tissue (w/v) was calculated and loaded onto the robot in a total volume of $400 \mu \mathrm{l}$ (using RLT buffer). RNA was eluted in $100 \mu$ l RNase free $\mathrm{dH}_{2} \mathrm{O}$ and stored at $-80^{\circ} \mathrm{C}$.

Reverse transcription: RNA was converted into cDNA using the TaqMan ${ }^{\circledR}$ Reverse Transcription Reagents kit (Applied Biosystems) as described previously (McBeath et al. 2007) using random hexamers and approximately $1 \mu \mathrm{g}$ RNA in double the reaction volume.

Real-time PCR: TaqMan ${ }^{\circledR}$ probe assays were performed on an Applied Biosystems 7000 Sequence Detection System programmed to conduct the following cycling profile: $37^{\circ} \mathrm{C}$ for $10 \mathrm{~min}, 95^{\circ} \mathrm{C}$ for $10 \mathrm{~min}$, followed by 45 cycles of $95^{\circ} \mathrm{C}$ for $15 \mathrm{~s}$ and $60^{\circ} \mathrm{C}$ for $1 \mathrm{~min}$ 
using the $2 \times$ SensiMix DNA Kit (Quantace). Reactions were conducted in a final volume of $20 \mu$ l containing $7.6 \mu \mathrm{l}$ cDNA template, $1 \times$ SensiMix (dU), $2.5 \mathrm{mM}$ $\mathrm{MgCl}_{2}, 1 \times$ Uracil DNA glycosylase, $900 \mathrm{nM}$ each primer and $250 \mathrm{nM}$ TaqMan ${ }^{\circledR}$ probe (Applied Biosystems). Four reactions were performed per sample: 1 reaction containing primers and probe for Atlantic salmon elongation factor one alpha (ELF; endogenous control) (Moore et al. 2005) and triplicate reactions containing primers and probe for ISAV segment 8 (Snow et al. 2006). Every 96-well reaction plate also contained 3 no-target controls (NTCs) per primer/probe set and a synthetic positive control (Snow et al. 2009). The fluorescence output for each cycle was measured and recorded upon completion of the entire run.

Characterisation of the segment 6 gene of ISAVpositive samples. Sequencing: Traditional PCR was performed to amplify a fragment of approximately $350 \mathrm{bp}$ of ISAV segment 6 encompassing the HPR using the primers HA FP FOR and HA FP REV (Table 1). Reactions (total volume $50 \mu \mathrm{l}$ ) containing $1 \times \mathrm{NH}_{4}$ buffer, $1.5 \mathrm{mM} \mathrm{MgCl}_{2}, 0.5 \mathrm{mM}$ dNTPs (Invitrogen), 28 pmol each primer and $2.5 \mathrm{U}$ Taq polymerase (Bioline) were subjected to cycling conditions of $94^{\circ} \mathrm{C}$ for $2 \mathrm{~min}$, followed by 40 cycles of $94^{\circ} \mathrm{C}$ for $1 \mathrm{~min}, 50^{\circ} \mathrm{C}$ for $1 \mathrm{~min}, 72^{\circ} \mathrm{C}$ for $1 \mathrm{~min}$ and a final extension step of $72^{\circ} \mathrm{C}$ for $5 \mathrm{~min}$. PCR products were visualised by electrophoresis through a 1\% agarose (Invitrogen) gel with ethidium bromide (Sigma) staining.

PCR products were purified using ExoSAP-IT PCR clean up (GE Healthcare) using $1 \mu \mathrm{l}$ reagent per $5 \mu \mathrm{l}$ sample and incubating at $37^{\circ} \mathrm{C}$ for $1 \mathrm{~h}$ followed by $80^{\circ} \mathrm{C}$ for $15 \mathrm{~min}$. Concentrations of purified products were estimated after electrophoresis through a $1 \%$ agarose gel alongside a Low DNA Mass Ladder (Invitrogen) and ethidium bromide staining.

Where PCR alone did not produce the necessary quantity of template for direct sequencing, the PCR products were ligated into the $\mathrm{pCR} 4-\mathrm{TOPO}$ vector and cloned in TOP-10 cells according to the manufacturer's protocol (Invitrogen). Plasmids were obtained from cul- tures using the QIAPrep Spin Miniprep kit (Qiagen) and concentrations estimated by electrophoresis as described above. Sequencing was performed as described above using the primers T7 (5'-TAA TAC GAC TCA CTA TAG GG-3') and T3 (5'-ATT AAC CCT CAC TAA AGG GA-3') in addition to HA FP FOR and HA FP REV.

A nested PCR approach was required to obtain the full sequence of the segment 6 open reading frame (ORF). The first round of PCR utilised the primers seg6ForXhoI and seg6RevSstII (Table 1) which included restriction enzyme sites that were not utilised in the present study. Reaction conditions were as described above with the exception of an extension step of $1 \mathrm{~min} 30 \mathrm{~s}$ and 45 cycles. Several sets of primers were utilised in the second round of PCR (Table 1) using $1 \mu \mathrm{l}$ of primary PCR product directly as template which produced overlapping products ranging from approximately 350 to $650 \mathrm{bp}$. Reaction conditions were as described above using an extension time of $1 \mathrm{~min}$ for all primer pairs. PCR products were purified using the MinElute Gel Extraction kit (Qiagen) according to the manufacturer's protocol and concentrations estimated as described above.

Purified products were sequenced using the primers shown in Table 1 and DTCS Quickstart mix on a Beckman Coulter $\mathrm{CEQ}^{\mathrm{TM}} 8800$ Genetic Analysis System according to the manufacturer's protocol. Resulting sequence was analysed using Sequencher software version 4.5 (Gene Codes).

Phylogenetic analysis. A BLAST search (http:// blast.ncbi. nlm.nih.gov/Blast.cgi) (Altschul et al. 1990) was conducted using the sequence obtained above to identify all other publicly available ISAV sequences of relevance to this analysis. A CLUSTALX (Larkin et al. 2007) multiple alignment was performed and the resultant alignment exported into BioEdit version 7.0.5.3 (Hall 1999). The alignment was manually edited and finally consisted of a region of 1001 nucleotides of the $\mathrm{N}$-terminal region of the ISAV HE sequence from 90 representative sequences, following the removal of duplicates. Due to the presence of gaps within the

Table 1. Primers used to obtain the segment 6 sequence

\begin{tabular}{|lll|}
\hline Name & Sequence $\left(5^{\prime}-3^{\prime}\right)$ & Source \\
\hline Seg6ForXhoI & CTCGAGATGGCACGATTCATAATTTTATTCC & - \\
Seg6RevSstII & CCGCGGAAGCAAAAGACAGGTTCGATGGT & - \\
HA FP FOR & CAGACATTGACTGGAGTAGAATTG & Cunningham et al. (2002) \\
HA FP REV & CTGCAATCCAAATACATGCCT & Cunningham et al. (2002) \\
S6F & CACCATGGCACGATTCATAATTT & Markussen et al. (2008) \\
s6IntR & CTTCAAAGGTGTCTGACACGTA & Markussen et al. (2008) \\
S6IntFor2 & TGACACTGATCAACGGATGC & - \\
S6IntRev2 & GCAGCTGTCATATTCACACG & - \\
S6IntFor3 & CGTGTGAATATGACAGCTGC & - \\
S6Rev2 & TCAAGCAACAGACAAGTTCG & - \\
S6IntRev3 & GTACCAGTCACTTGGAAACC & \\
\hline
\end{tabular}


many different sequences, the 1001 region used in this analysis could not contain the HPR region itself. The phylogenetic relationship among ISAV isolates was inferred from single representatives of each sequence obtained, using a maximum likelihood approach implemented within PAUP* (version 4.0b8; Swofford 1993). For presentational purposes, following classification of the sequence identified within the present study as an EU-G2 type sequence (Nylund et al. 2007), a reduced data set was prepared including 4 to 5 representative sequences from each of the previously established genetic subgroups (Nylund et al. 2007). As per the original analysis, this reduced data set was examined using the MODELTEST program (Posada \& Crandall 1998) in order to identify the model that best fit the sequence data from 56 models using Akaike's information criterion (AIC; Akaike 1974). This model was defined as: rate matrix of $\mathrm{A}$ to $\mathrm{C}=2.3935$, $\mathrm{A}$ to $\mathrm{G}=$ 5.2797, $\mathrm{A}$ to $\mathrm{T}=00.9570, \mathrm{C}$ to $\mathrm{G}=0.2842, \mathrm{C}$ to $\mathrm{T}=$ 7.7884 and $\mathrm{G}$ to $\mathrm{T}=1.0000$; base frequencies $\mathrm{A}=$ $0.2924, \mathrm{C}=0.2029, \mathrm{G}=0.2525, \mathrm{~T}=0.2522$; proportion of invariable sites $(\mathrm{I})=0.5831$.

The optimum tree generated using the maximum likelihood distances was identified using the heuristic search option implemented in PAUP*. Confidence in the resultant tree topology was assessed using 100 bootstrap iterations (Felsenstein 1985). Significant bootstrap values for the major clades were transferred to the tree derived from the original data.

\section{RESULTS}

\section{Surveillance of Scottish marine Atlantic salmon farms for ISAV}

Of 36 Atlantic salmon marine aquaculture sites screened for the presence of ISAV RNA using the segment 8 real-time PCR assay, 4 sites proved positive $(11.1 \%)$ (Table 2$)$. All positive samples originated from the Scottish mainland, with 3 in NWM and 1 in SWM. No positives were identified in samples originating in OS or WI. A sample was only deemed positive for ISAV following detection of viral RNA in all 3 of the triplicate quantitative PCR (qPCR) reactions. All positives resulted from gill tissue (ELF mean $\pm \mathrm{SD}$ cycle threshold $[\mathrm{Ct}]$ value $=$ $17.24 \pm 0.45$ ). Of the 4 sites, 1 collected in May 2007 resulted in all 3 gill tissue pools positive (mean Ct values: NWM10 p1, $36.59 \pm 0.95 ; \mathrm{p} 2,29.69 \pm 0.55 ; \mathrm{p} 3,32.50 \pm 1.5$ ) and the remaining 3 sites had only 1 positive pool in each (NWM7 p1, 35.56 \pm 0.36 ; NWM2 p1, $35.93 \pm 1.2$; SWM17 p3, $36.53 \pm 1.18$, collected in November 2006, April 2007 and November 2007, respectively); thus 5.6\% ( 6 out of 108) of the total gill tissue pools were positive.

\section{Characterisation of the segment 6 gene of ISAV-positive samples}

\section{Sequencing}

DNA sequencing of the variable region of segment 6 was attempted on the ISAV-positive gill tissue samples. A $296 \mathrm{bp}$ sequence was obtained from each of the NWM10 and NWM7 samples. The HPR amino acid translation of these identical sequences confirmed the presence of an ISAV HPR0 subtype (Table 3). The sequence in this region differed by 2 amino acids from the previously described Scottish HPR0 (Cunningham et al. 2002) at HPR positions 24 and 25, where serine and threonine have replaced alanine and asparagine, respectively. The NWM10 and NWM7 amino acid sequence fragments were identical to one originating in Maine, USA (AY973194) (Nylund et al. 2007), and New Brunswick, Canada (Cook-Versloot et al. 2004).

Due to the very low levels of genetic material detected in the positive samples, full segment 6 sequencing was only completed on NWM10 p2. A $1236 \mathrm{bp}$ sequence encompassing the full length ORF of segment 6 was obtained and submitted to GenBank

Table 2. Number of sites from which gill and heart samples were received and tested for infectious salmon anaemia virus using real-time PCR targeting segment 8. Positives were detected in gill samples only. SWM: southwest mainland; NWM: northwest mainland; WI: Western Isles; OS: Orkney \& Shetland Isles. Mean \pm SD cycle threshold $(\mathrm{Ct})$ values shown $(\mathrm{n}=3)$

\begin{tabular}{lccc}
\hline Area & No. of sites tested & Results & Ct values (area code) \\
\hline SWM & 6 & 1 positive site & $36.53 \pm 1.18$ (SWM17) \\
NWM & 13 & 3 positive sites & $35.93 \pm 1.2($ NWM2) \\
& & & $35.56 \pm 0.36($ NWM7) \\
WI & 6 & Negative & $36.59 \pm 0.95,29.69 \pm 0.55,32.50 \pm 1.5($ NWM10) \\
OS & 11 & Negative & - \\
Total & 36 & - & - \\
a This site positive in all 3 tissue pools & & \\
\end{tabular}




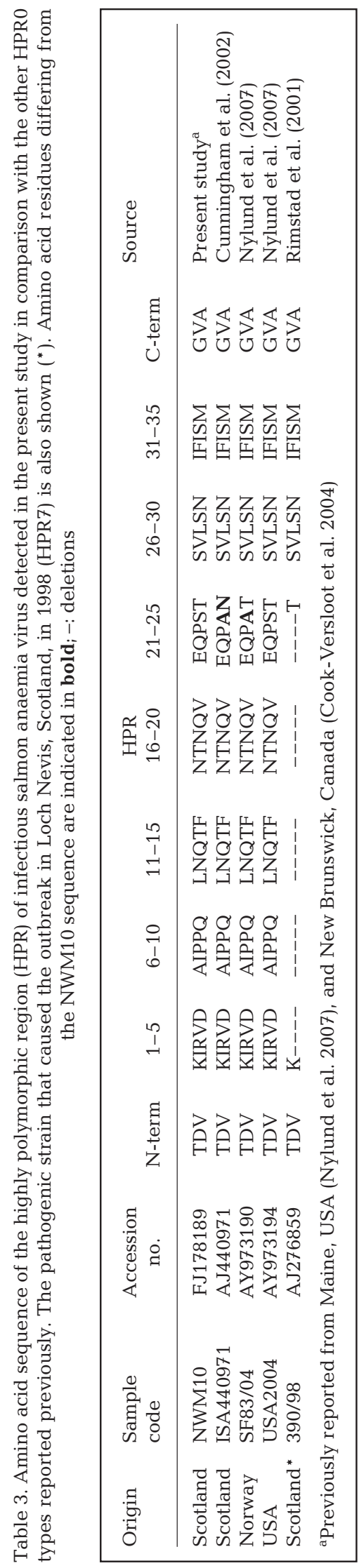

(FJ178189). The full sequence was most similar to that described by Nylund et al. (2007) originating from Maine (isolate USA2004) with a total of $10 \mathrm{bp}$ mismatches resulting in 2 amino acid changes. When compared with a recently reported Norwegian HPR0, EU118820 (Markussen et al. 2008), the NWM10 sequence had $40 \mathrm{bp}$ substitutions resulting in 5 amino acid changes. An alignment of NWM10 with the pathogenic Nevis strain, AJ276859 (Rimstad et al. 2001), the cause of the Scottish outbreak in 1998, showed $38 \mathrm{bp}$ differences which resulted in 7 amino acid changes in addition to the HPR deletion.

\section{Phylogenetic analysis}

The genetic relationships among NWM10 and representative ISAV sequences from each proposed genogroup (Nylund et al. 2007) are illustrated in the maximum-likelihood derived phylogeny depicted in Fig. 1. The results and those of the wider analysis including all available sequences (data not shown) indicate strong support for 1 European ISAV group and 1 North American group. Results supported by strong bootstrap values indicated that the sequence derived from NWM10 clustered with a small set of HPR0 and HPR3 ISAV sequences in the group designated EU-NS within EU-G2 (Nylund et al. 2007), which include European-type sequences originating from Atlantic salmon farms in North America.

\section{DISCUSSION}

The present study presents evidence for the presence of detectable levels of ISAV HPR0 RNA in approximately $10 \%$ of the Scottish marine Atlantic salmon production sites sampled. This extends the known distribution of HPR0, the presence of which had previously been described in wild and farmed fish in Scotland (Cunningham et al. 2002, FRS 2005), Norway (Plarre et al. 2005, Nylund et al. 2007), North America (Cook-Versloot et al. 2004) and the Faroe Islands (Christiansen \& Østergård 2007).

The results obtained indicate the presence of very low levels of viral RNA which were detectable only in gill and not in heart tissues. Previous studies have supported high levels of viral detection in gills (FRS 2005), which were selected for sampling on this basis. Pooling of samples was employed for practical purposes, which could have resulted in reduced sensitivity. Replicated results from highly controlled assays coupled to subsequent genetic characterisation of the HE gene in some cases, however, support the reported findings. 


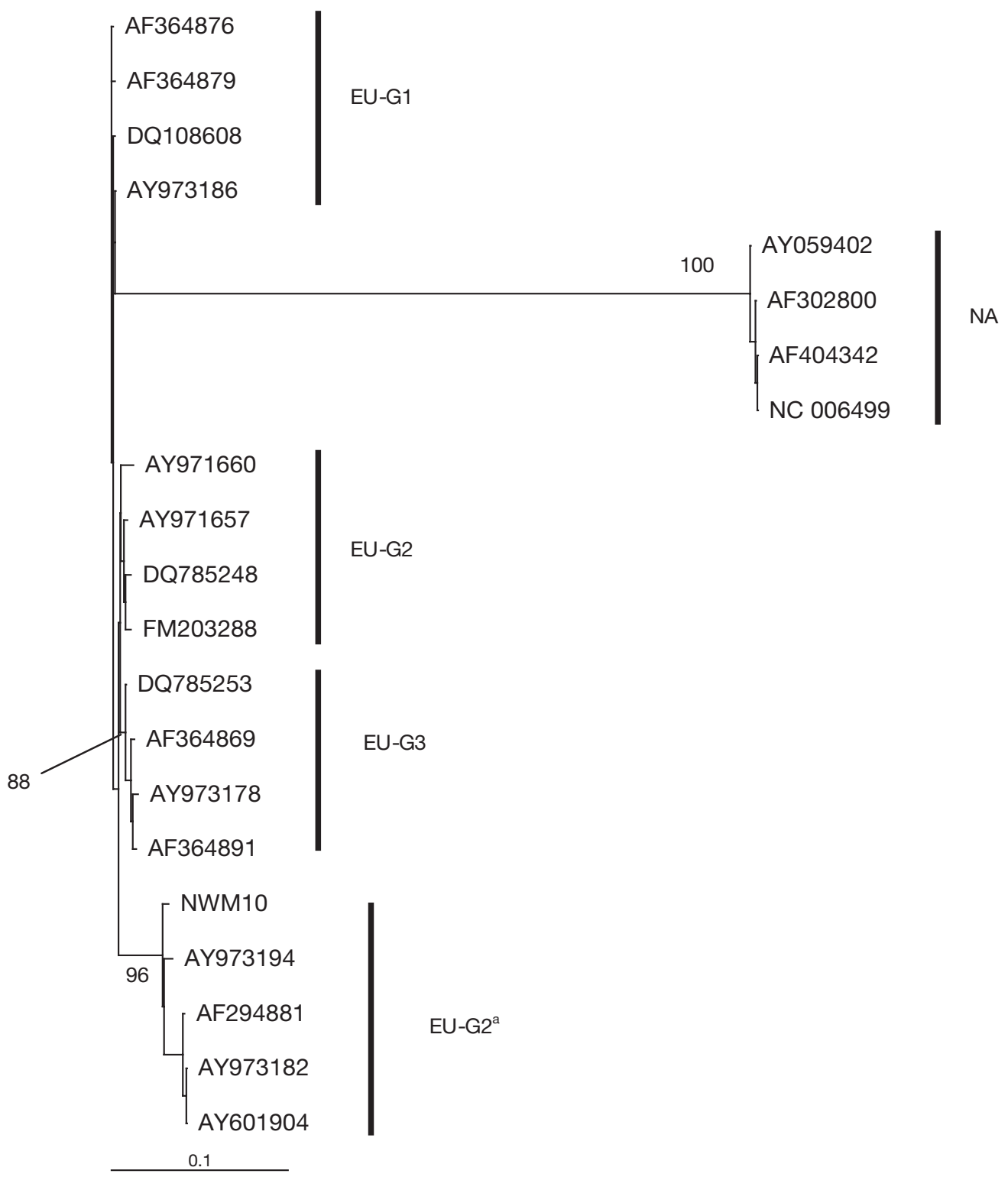

Fig. 1. Genetic relationships among NWM10 and selected infectious salmon anaemia virus sequences from each phylogenetic group (Nylund et al. 2007) indicated by maximum-likelihood and parsimony analysis derived phylogeny. All sequences form the European group (EU); subgroups are displayed as EU-G1 to -G3 with the exception of the North American group (NA).

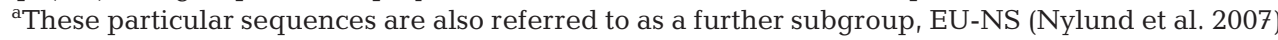

To date, the isolation of the HPR0 ISAV variant in ISAV permissive cell lines has not been reported and its presence has only been demonstrated in apparently healthy fish using PCR-based methods. This evidence, coupled to a different tissue tropism with HPR0 largely being detected in gill tissues, suggests that HPR0 differs in its fundamental biological properties to variants which are responsible for outbreaks of disease in Atlantic salmon. It is tempting to speculate that these biological differences may be directly linked to HPR0 alteration of the ISAV HE protein stalk region, although this remains to be definitively demonstrated. Similar alterations in paramyxoviruses can lead to differences in important virulence-related factors such as receptor specificity and cellular tropism (de Leeuw et al. 2005) and, in influenza neuraminidase, stalk length has been correlated with replication efficiency (Castrucci \& Kawaoka 1993).

While ISAV HPR0 may not directly cause disease, increasing evidence suggests that disease-causing variants of ISAV may have evolved from HPR0-like ancestors on multiple independent occasions. HPR0 
sequences are present in each of the 3 main European subgroups described by Nylund et al. (2007) and shown in the wider analysis of the present study (data not shown). According to Nylund et al. (2007) the emergence of a pathogenic variant from an endemic reservoir of ISAV HPR0 may be based on a stochastic event that is dependent on the replication frequency of the virus and the time available for changes in the HPR of the HE gene to occur. The number of HPR variants characterised to date is testament to the adaptability of ISAV and indicative of such changes occurring relatively frequently. The maintenance of an HPR0 reservoir on marine aquaculture farms thus represents a likely risk factor in the emergence of ISA disease.

The localisation of positive detections to mainland Scotland, in particular the northwest, was not statistically significant and likely reflected the non-random nature of the sampling strategy. The anonymous nature of the sampling also makes epidemiological follow-up difficult.

At least 2 geographical reservoirs of ISAV, a North American subtype (NA-ISAV) and a European subtype (EU-ISAV), have previously been suggested (Nylund et al. 2007). The 2 broad groupings were supported by the present study which classified the ISAV HPR0 subtype detected here within the European clade. The HPR0 sequence type identified here has not been reported previously in Europe but is very similar to a type originating in Maine, USA (AY973194), which was not associated with ISA-induced mortality (Nylund et al. 2007) and also in asymptomatic fish from New Brunswick, Canada (AY646060-AY646061) (Cook-Versloot et al. 2004). Interestingly, the other 3 sequences within this small cluster (EU-NS) AF294881 (Kibenge et al. 2001b), AY973182 (Nylund et al. 2007) and AY601904 (Devold et al. 2006) - are from HPR3-type viruses which were associated with ISA disease (Nylund et al. 2007). The origin of these viruses might thus be traced to an HPR0 ancestor similar to that characterized in the present study. The relative efficiency of horizontal transmission of virulent ISA viruses, however, makes it difficult to determine whether this cluster represents multiple independent emergences or a single emergence followed by horizontal transmission of the virulent virus.

Molecular epidemiological analysis suggests that viruses in subgroup EU-NS, despite being isolated from salmon farms in North America, most likely resulted from transfer of a European-type virus to this region, possibly as a result of anthropogenic activity (Nylund et al. 2007). The present study further supports this hypothesis by identifying closely related sequences currently in circulation within Europe. Despite the fact that 1.8 million Atlantic salmon ova (A. Warwick, Marine Scotland Fish Health Inspec- torate, pers. comm.) have been imported to Scotland from the US in recent years, no evidence of transfer of North American subtypes of ISAV was identified in the present study. It remains feasible, however, that European viruses in circulation in North America could have been returned to Scotland through such a mechanism.

Vertical or transgenerational transmission of avirulent ISAV isolates has been proposed as a mechanism for maintenance of ISAV HPR0 within Atlantic salmon populations in Norway (Nylund et al. 2007). Evidence of vertical transmission of ISAV in Chile has also recently been published (Vike et al. 2009). Another proposed transmission route is that of infection from wild marine and freshwater sources. To date, ISAV has been detected in healthy wild salmonid species in Scotland (Raynard et al. 2001, Cunningham et al. 2002) and Norway (Plarre et al. 2005). Whether marine farmed Atlantic salmon pick up HPR0 infection from wild reservoirs that have been shown to harbour ISAV HPR0 or whether infection is sustained in farmed fish populations is unclear.

It is also unclear where the previously reported HPR0s from Scotland would fit into Fig. 1, as in both cases only partial sequencing of the HPR was performed (Cunningham et al. 2002, FRS 2005). However, the results do suggest that the cause of the Scottish outbreak in 1998, Nevis AJ276859 (Rimstad et al. 2001), probably did not arise directly from an NWM10 HPR0-like ancestor. The origin of the disease outbreak was never explained with certainty, but 2 hypotheses were put forward: accidental transportation from an infected area or emergence from a wild reservoir. In the latter case, emergence may have occurred from an as-yet uncharacterised HPR0 in Scotland.

Evidence for the presence of a putatively avirulent ISAV HPR0 virus in Scottish Atlantic salmon farms is of concern in relation to the risk of reemergence of ISA disease in Scotland. The fast evolution rate of viruses and suggested hypothesis for deletions or reassortment giving rise to pathogenic strains underlines the requirement for maintenance of a vigilant surveillance regime for ISAV in Scotland. It also highlights the role of good husbandry practice in limiting the long-term maintenance of HPR0 within populations and thus reducing the opportunity for evolution and emergence of disease-causing ISAV variants. Further research, including understanding the distribution of the agent in freshwater production, is fundamental to understanding the likely origin, maintenance and risk posed by ISAV HPR0 to Scottish Atlantic salmon aquaculture.

Acknowledgements. The involvement of the anonymous farms within the industry who allowed the provision of samples is greatly appreciated. Thanks also to the Marine Scotland Fish Health Inspectorate for carrying out the sampling. 


\section{LITERATURE CITED}

Akaike H (1974) A new look at statistical model identification. IEEE Trans Auto Control 19:716-723

> Altschul SF, Gish W, Miller W, Myers EW, Lipman DJ (1990) Basic local alignment search tool. J Mol Biol 215:403-410 Anonymous (2000) ISA hits the Faroes. Fish Farming Int 27:47

- Aspehaug V, Mikalsen AB, Snow M, Biering E, Villoing S (2005) Characterization of the infectious salmon anemia virus fusion protein. J Virol 79:12544-12553

Bouchard D, Keleher W, Opitz HM, Blake S, Edwards KC, Nicholson BL (1999) Isolation of infectious salmon anemia virus (ISAV) from Atlantic salmon in New Brunswick, Canada. Dis Aquat Org 35:131-137

Bouchard DA, Brockway K, Giray C, Keleher W, Merrill PL (2001) First report of infectious salmon anaemia (ISA) in the United States. Bull Eur Assoc Fish Pathol 21:86-88

> Castrucci MR, Kawaoka Y (1993) Biologic importance of neuraminidase stalk length in influenza A virus. J Virol 67:759-764

Christiansen DH, Østergård PS (2007) Genetic characterisation of infectious salmon anaemia virus (ISAV) highly polymorphic region subtype 0 (HPR0) in Faroe Islands. EAFP 13th Int Conf Fish Shellfish Dis, Grado, Italy

Cook-Versloot M, Griffiths S, Cusack R, McGeachy S, Ritchie $R$ (2004) Identification and characterisation of infectious salmon anaemia virus (ISAV) haemagglutinin gene highly polymorphic region (HPR) type 0 in North America. Bull Eur Assoc Fish Pathol 24:203-208

Cunningham CO, Gregory A, Black J, Simpson I, Raynard RS (2002) A novel variant of the infectious salmon anaemia virus (ISAV) haemagglutinin gene suggests mechanisms for virus diversity. Bull Eur Assoc Fish Pathol 22:366-374

de Leeuw OS, Koch G, Hartog L, Ravenshorst N, Peeters BP (2005) Virulence of Newcastle disease virus is determined by the cleavage site of the fusion protein and by both the stem region and globular head of the haemagglutininneuraminidase protein. J Gen Virol 86:1759-1769

$>$ Devold M, Falk K, Dale OB, Krossøy B and others (2001) Strain variation, based on the hemagglutinin gene, in Norwegian ISA virus isolates collected from 1987 to 2001: indications of recombination. Dis Aquat Org 47:119-128

Devold M, Karlsen M, Nylund A (2006) Sequence analysis of the fusion protein gene from infectious salmon anemia virus isolates: evidence of recombination and reassortment. J Gen Virol 87:2031-2040

Einer-Jensen K, Ahrens P, Forsberg R, Lorenzen N (2004) Evolution of the fish rhabdovirus viral haemorrhagic septicaemia virus. J Gen Virol 85:1167-1179

Falk K, Aspehaug V, Vlasak R, Endresen C (2004) Identification and characterization of viral structural proteins of infectious salmon anemia virus. J Virol 78:3063-3071

Felsenstein J (1985) Confidence limits on phylogenies: an approach using the bootstrap. Evolution 39:783-791

FRS (Fisheries Research Services) (2005) Epizootiological investigation into a case of suspicion of infectious salmon anaemia (ISA) in Scotland in November 2004. Fisheries Research Services, Aberdeen

FRS (Fisheries Research Service) (2009) ISA news releases. Fisheries Research Service, Aberdeen, available at www. frs-scotland.gov.uk/Delivery/standaloneM.aspx? contentid= 3259

Godoy MG, Aedo A, Kibenge MJ, Groman DB and others (2008) First detection, isolation and molecular characterization of infectious salmon anaemia virus associated with clinical disease in farmed Atlantic salmon (Salmo salar) in Chile. BMC Vet Res 4:28
Hall TA (1999) BioEdit: a user-friendly biological sequence alignment editor and analysis program for Windows 95/98/NT. Nucleic Acids Symp Ser 41:95-98

> Kibenge FSB, Gárate ON, Johnson G, Arriagada R, Kibenge MJT, Wadowska D (2001a) Isolation and identification of infectious salmon anaemia virus (ISAV) from Coho salmon in Chile. Dis Aquat Org 45:9-18

Kibenge FS, Kibenge MJ, McKenna PK, Stothard P, Marshall R, Cusack RR, McGeachy S (2001b) Antigenic variation among isolates of infectious salmon anaemia virus correlates with genetic variation of the viral haemagglutinin gene. J Gen Virol 82:2869-2879

> Kibenge FS, Kibenge MJ, Wang Y, Qian B, Hariharan S, McGeachy S (2007) Mapping of putative virulence motifs on infectious salmon anemia virus surface glycoprotein genes. J Gen Virol 88:3100-3111

Krossøy B, Devold M, Sanders L, Knappskog PM and others (2001) Cloning and identification of the infectious salmon anaemia virus haemagglutinin. J Gen Virol 82:1757-1765

- Larkin MA, Blackshields G, Brown NP, Chenna R and others (2007) Clustal W and Clustal X version 2.0. Bioinformatics 23:2947-2948

> Lovely JE, Dannevig BH, Falk K, Hutchin L and others (1999) First identification of infectious salmon anaemia virus in North America with haemorrhagic kidney syndrome. Dis Aquat Org 35:145-148

> Markussen T, Jonassen CM, Numanovic S, Braaen S, Hjortaas M, Nilsen H, Mjaaland S (2008) Evolutionary mechanisms involved in the virulence of infectious salmon anaemia virus (ISAV), a piscine orthomyxovirus. Virology 374:515-527

- McBeath AJA, Snow M, Secombes CJ, Ellis AE, Collet B (2007) Expression kinetics of interferon and interferoninduced genes in Atlantic salmon (Salmo salar) following infection with infectious pancreatic necrosis virus and infectious salmon anaemia virus. Fish Shellfish Immunol 22:230-241

> Mjaaland S, Rimstad E, Falk K, Dannevig BH (1997) Genomic characterization of the virus causing infectious salmon anemia in Atlantic salmon (Salmo salar L.): an orthomyxolike virus in a teleost. J Virol 71:7681-7686

Mjaaland S, Hungnes O, Teig A, Dannevig BH, Thorud K, Rimstad E (2002) Polymorphism in the infectious salmon anemia virus hemagglutinin gene: importance and possible implications for evolution and ecology of infectious salmon anemia disease. Virology 304:379-391

Mjaaland S, Markussen T, Sindre H, Kjoglum S, Dannevig BH, Larsen S, Grimholt U (2005) Susceptibility and immune responses following experimental infection of MHC compatible Atlantic salmon (Salmo salar L.) with different infectious salmon anaemia virus isolates. Arch Virol 150: 2195-2216

> Moore LJ, Somamoto T, Lie KK, Dijkstra JM, Hordvik I (2005) Characterisation of salmon and trout CD8 $\alpha$ and CD8 $\beta$. Mol Immunol 42:1225-1234

Mullins JE, Groman DB, Wadowska D (1998) Infectious salmon anaemia in salt water Atlantic salmon (Salmo salar L.) in New Brunswick, Canada. Bull Eur Assoc Fish Pathol 18:110-114

Nylund A, Plarre H, Karlsen M, Fridell F, Ottem KF, Bratland A, Saether PA (2007) Transmission of infectious salmon anaemia virus (ISAV) in farmed populations of Atlantic salmon (Salmo salar). Arch Virol 152:151-179

> Plarre H, Devold M, Snow M, Nylund A (2005) Prevalence of infectious salmon anaemia virus (ISAV) in wild salmonids in western Norway. Dis Aquat Org 66:71-79

Posada D, Crandall KA (1998) MODELTEST: testing the 
model of DNA substitution. Bioinformatics 14:817-818

Raynard RS, Murray AG, Gregory A (2001) Infectious salmon anaemia virus in wild fish from Scotland. Dis Aquat Org 46:93-100

Rimstad E, Mjaaland S, Snow M, Mikalsen AB, Cunningham CO (2001) Characterization of the infectious salmon anemia virus genomic segment that encodes the putative hemagglutinin. J Virol 75:5352-5356

Rodger HD, Turnbull T, Muir F, Millar S, Richards RH (1998) Infectious salmon anaemia (ISA) in the United Kingdom. Bull Eur Assoc Fish Pathol 18:115-116

Snow M, McKay P, McBeath AJ, Black J and others (2006) Development, application and validation of a TaqMan ${ }^{\circledR}$ real-time RT-PCR assay for the detection of infectious

Editorial responsibility: Mark Crane,

Geelong, Victoria, Australia salmon anaemia virus (ISAV) in Atlantic salmon (Salmo salar). Dev Biol 126:133-145

Snow M, McKay P, Matejusova I (2009) Development of a widely applicable positive control strategy to support detection of infectious salmon anaemia virus (ISAV) using TaqMan real-time PCR. J Fish Dis 32:151-156

Swofford DL (1993) PAUP: Phylogenetic analysis using parsimony, Version 3.1. Illinois Natural History Survey, Champaign, IL

Thorud K, Djupvik HO (1988) Infectious anaemia in Atlantic salmon (Salmo salar L.). Bull Eur Assoc Fish Pathol 8:109-111

Vike S, Nylund S, Nylund A (2009) ISA virus in Chile: evidence of vertical transmission. Arch Virol 154:1-8

Submitted: February 19, 2009; Accepted: August 7, 2009

Proofs received from author(s): November 13, 2009 